\title{
Reflexiones sobre las prácticas actorales \\ contemporáneas. Una posible mirada sobre el teatro independiente en Córdoba (Argentina)
}

\section{Gabriela Macheret}

Universidad Nacional de Córdoba

Y es que mostrar las determinaciones históricas de lo que somos es mostrar lo que hay que hacer. Porque somos más libres de lo que creemos, y no porque estemos menos determinados, sino porque hay muchas cosas con las que aún podemos romper, para hacer de la libertad un problema estratégico, para crear libertad. Para liberarnos de nosotros mismos.

Michel Foucault

\section{RESUMEN}

Este ensayo presenta un panorama general sobre los diversos modos de hacer teatro independiente en Córdoba, Argentina, a partir de la década de 1990. Se plantea que las características sobresalientes son la multiplicidad, la heterogeneidad y el uso de varios medios, incluyendo la tecnología, sin que uno privilegie el otro.

\section{PALABRAS CLAVE}

Argentina, teatro independiente, identidad, sujeto fragmentado, crisis, posmodernidad, caos, creación colectiva, canon de la multiplicidad, teatro catástrofe.

\section{ABSTRACT}

This essay presents a general panorama on the diverse ways of making independent theater in Cordoba, Argentina, since the decade of the 1990s. The overriding characteristics are plurality (multiplicity), heterogeneous nature and the use of various media sources, including technology, without favoring any such characteristic.

\section{KEY WORDS}

Argentina, independent theater, identity, fragmented subject, crisis, post modernity, chaos, collective creation, canon of multiplicity, catastrophe theatre. 


\section{Introducción}

El interés de este trabajo es la reflexión sobre las estéticas que circulan en el teatro independiente actual. Considerando que las producciones del arte independiente conforman un entramado que constituye el discurso de una época, creo indispensable pensarnos en la práctica, pero también dentro los regímenes discursivos que ponemos a circular. Me enfoco en la ciudad de Córdoba, pero entendiendo que compartimos circunstancias similares con otras realidades latinoamericanas, a partir de los contextos históricos y sociales que nos unen. Por eso, pensar en las estéticas y en los discursos en y sobre esas estéticas del teatro actual - ya sea en la ciudad de Córdoba o en cualquier otro lugar $y$, en particular, en el teatro independiente- no significa la búsqueda de una supuesta identidad escénica, que definiría una teatralidad local. La noción de identidad como concepto cerrado, capaz de volver las cosas definibles y clasificables, creo no tiene ya lugar, al menos en lo que al arte se refiere.

Tomando algunas categorías deleuzianas en relación con este tema, podemos pensar que el «otro» es siempre la primera referencia, en tanto es un punto de vista que viene a afectar al sujeto distinguiéndolo, dándole, precisamente, identidad. Pero los sujetos están cada vez más separados de los otros en el sistema de relaciones de la sociedad actual. De esta forma de concebir una identidad resulta, para Deleuze, un sujeto fragmentado, abierto a muchas posibles individuaciones y aquí entra el tema de la verdad. La verdad ya no estaría ligada a los conceptos de identidad y de reconocimiento; sería, en cambio, la puesta en perspectiva de múltiples y distintas posibilidades: es distancia, divergencia, es «diferencia ética», el valor dado a diferentes formas de existencia.

Lo que cuenta entonces es la creación de espacios que nos permitan pensarnos colectiva e individualmente, por un lado, como comunidad que es afectada en forma constante por otras comunidades con las que la vinculan relaciones de fuerza, al tiempo que soporta tensiones al interior de su propio campo; $y$, por el otro, como sujetos individuales dentro de esa comunidad, de ese campo. En términos de Deleuze, toda efectuación es producto de afectos, de fuerzas que nos impactan, y crean una necesidad que nos conduce a una búsqueda. Pero ¿cuál es la búsqueda, desde dónde se parte al iniciarla, dónde creemos que podríamos llegar?, ¿cuál es el ángulo desde el que se que mira la realidad en esa búsqueda y qué nociones surgen para definirla? Me interesa pensar las estéticas actuales como procesos en devenir, en movimiento. Cuando hablo de estética, me refiero al sentido aristotélico del término poiesis y el doble aspecto que designa: como teoría, conocimiento; y como hacer, creación. Desde este punto de vista, se define un hacer que se refiere no tanto a convertir 
pensamientos en materia, sino a un pensamiento en la materia. Pensamiento como actividad, materia que deviene en procedimientos que se realizan por una actividad impulsada por el pensamiento. Pensar, hacer, dar forma: crear. Y si preferimos en sentido deleuziano, diremos que «Pensar es crear, no hay otra creación, pero crear es, primero, engendrar "pensar" en el pensamiento» (Zourabichvili 2004: 83).

La estética teatral sería entonces la materialidad de un pensamiento en ese sentido, puesta en forma de ideas sobre el mundo, pero esas ideas se materializan no solo estéticamente en poéticas que son la puesta en acto de los pensamientos, sino también en discursos que, a su vez, son constructores de formas estéticas. Lo que se hace y lo que se dice en relación con lo que se hace se engendran mutuamente. No solo se puede pensar a través de los discursos, sino que los mismos regímenes discursivos deben ser pensados, pero pensados menos como «secuencias de ideas», que como «constelaciones» de ideas que determinan un tema, «constelaciones de momentos que van cambiando históricamente», según Adorno (Adorno 2004: 10). En Arqueología del saber, Michel Foucault define el saber como el conocimiento que es aceptado por una comunidad en un momento determinado. Dice: «no puede configurarse un elemento de saber si [...] no está dotado de los efectos de coerción típicos de lo que está validado como científico, o simplemente racional o comúnmente admitido» (Foucault 1979: 54-55). Foucault pone en relación el problema del conocimiento con el poder, pero no habla de un poder que afecta desde el exterior, sino de la tensión de fuerzas que se da al interior de los regímenes discursivos y agrega: «no se trata de saber cuál es el poder que pesa desde el exterior sobre la ciencia», que yo hago análogo al arte, sino «su régimen interno de poder; y de qué modo y por qué, en ciertos momentos, estos se modifican de manera global» (Foucault 1979: 143-44). Debemos pensar entonces cuáles son los regímenes discursivos que circulan en relación con la práctica teatral y a la vez la construyen; pensar el teatro no como un objeto externo que debe ser analizado, sino pensarnos nosotros mismos dentro y con el objeto.

\section{El canon teatral contemporáneo: una presencia ausente}

En las últimas décadas, el teatro ha experimentado un proceso de transformación. Estos cambios se advierten en lo referido a la dramaturgia, a los modos de producción, a la actuación y a todas las disciplinas que intervienen en la conformación del hecho teatral. El teatro parece encontrarse en un momento en que toda certeza es desarticulada. Pero el teatro no es un hecho aislado y da cuenta del mundo en el que está inserto; es, incluso, una manera de mirar el mundo y colabora en su construcción. 
Georges Balandier plantea que «la vida intelectual de los últimos años es un ingreso en la era del vacío» (Balandier 1998: 146). A este vacío lo caracteriza como el del pensamiento fragmentado, roto, como aquel «espejo trizado» del que hablara José Joaquín Brunner, donde el orden se desdibuja en los cambios permanentes, donde lo real se esconde bajo la forma de simulación, donde la única certeza es el movimiento. La nueva modernidad o posmodernidad produce para él lo desconocido, una suerte de extrañamiento en el que el hombre ya no es capaz de reconocer sus propias creaciones y tampoco puede reconocerse a sí mismo. Creo que este estado que describe define acabadamente la época que nos toca (o que nos hemos creado), y da cuenta de la impotencia que muchas veces experimenta el arte cuando vuelve la mirada a sí mismo y al mundo. El teatro en Córdoba, desde la década de 1980, parece centrar su reflexión en esta crisis: la de la palabra, la de la representación, la de las relaciones y el modo organizacional del mundo basado en supuestos decadentes; y plantea distintas respuestas, múltiples resoluciones, a través del juego con diferentes formas de lenguaje. Hay que señalar que en la década de 1980, en Argentina, tuvo lugar el fin de la última dictadura militar y el advenimiento de la democracia.

Creo que los modos de construcción a los que asistimos en el teatro de las últimas décadas encuentran correspondencia con teorías como las del desorden, el caos, la complejidad. Balandier, por ejemplo, introduce la noción de "caos fecundo», en el sentido de que existen "probabilidades» de construir un orden a partir del desorden; sobre la idea de "puntos de bifurcación» capaces de establecer modificaciones sustanciales a todo un sistema y de crear formas que actúan como «atraedores extraños» (Balandier 1998: 52-53). Encuentro en estos conceptos correspondencias con la propuesta «atomística» que marca la teatralidad contemporánea, con la fragmentación de su estructura, con la confrontación de distintos elementos que conviven en sus poéticas, con las lógicas particulares que inauguran. Balandier habla de «unir dos sistemas diferentes, aparentemente incoherentes, en otro lenguaje que los sobrepasa y contribuye a explicarlos» (Balandier 1998: 56). Es de este modo que se concreta la estructura y el sentido en la mayor parte de las obras que se ponen en escena: diferentes líneas estéticas que se entrecruzan; multiplicidad de lenguajes; distintos planos temporales y espaciales que confluyen, que se mezclan hasta borrar algunas categorías.

También Balandier advierte nuevas características que ingresan en la ficción contemporánea, aplicables, en mi opinión, a las estéticas teatrales que tienen lugar desde hace ya varias décadas en Córdoba, como son: la mezcla de categorías, la asociación de los contrarios, la inversión de los 
términos de una relación, de lo cual «resulta la evocación de un mundo al revés, de un universo del cual se ha adueñado el desorden» (Balandier 1998: 116). Creo que un teatro que mezcla las categorías, que permite asociar los opuestos, que invierte las figuras de poder, es un teatro que se permite pensar el mundo detrás de su apariencia, que intenta imaginar alternativas al orden social establecido: el trabajo en forma simultánea con distintos elementos estéticos para ser confrontados; el desafío de las tendencias particulares de cada sujeto, puestas a dialogar con aquellas que se reconocen como ajenas y aun con las que, a priori, en otras décadas, eran rechazadas. Son esas miradas las que permiten recurrir a una diversidad de conceptos como herramientas de construcción; involucrarse con el espectador como un sujeto activo; eliminar las categorías de tiempo, de espacio, de sentido unívoco: multiplicidad de sentidos, todas categorías combinables, sin jerarquías preestablecidas.

La mayor modificación que sufrió la escena en el siglo anterior se vincula con el sentido y el concepto de representación; desde allí, ninguno de sus elementos volvería ya a ser concebido bajo los mismos presupuestos. Las relaciones de espacio y tiempo en términos de sucesión y linealidad se modificaron y produjeron la espacialización del tiempo y la temporalización del espacio; la noción de personaje se alejó del concepto mimético. La idea de textualidad se abrió a un sinnúmero de posibilidades: se destituyó el lugar jerárquico otorgado a la palabra por sobre los demás elementos; se puso en cuestión la función especular, el cuerpo se volvió central en algunos casos, asociado al artefacto en otros. Podemos reconocer en estos cambios, en los diversos modos representacionales, distintos cánones de teatralidad correspondientes a dos momentos definidos como modernidad y posmodernidad.

Prieto Stambaugh, en su artículo «Performance y teatralidad liminal: hacia la represent-acción» sostiene: «A partir de los años 80, el posmodernismo propuso una revisión crítica de la representación mediante la deconstrucción del impulso mimético como principio epistemológico para la creación» (Prieto Stambaugh 2007: 1). Este proceso tuvo lugar en nuestra ciudad con sus singularidades. En los años 80 la llamada creación colectiva, silenciada en los 70 a instancias de la dictadura, de alto contenido político, se reeditaba con otros nombres, y con ella una dramaturgia escénica que había intentado hacer desaparecer la figura del autor, ligado a la noción de propiedad, asociado al teatro realista-naturalista, considerado producto de consumo de la burguesía por excelencia.

En la década de 1990 asistimos a la irrupción de las nuevas tecnologías. Los efectos de la globalización y el impacto de los medios masivos de comunicación se introducen en el teatro local, dando cuenta de los 
nuevos sistemas de relaciones que comenzaban a construirse, del nuevo lugar del sujeto en el mundo. La débil frontera entre realidad y ficción que se percibe en la dinámica social es asumida por el teatro, que borra a su vez sus propios límites, como una mirada crítica sobre el entramado de poder que construye la realidad. Las nuevas propuestas poéticas tienen nombre y apellido, como alguna vez había ocupado el centro el autor y luego el director para diluirse en el grupo: ahora otra vez el director es el que marca el camino, el referente de tal o cual tendencia.

Estoy de acuerdo con Sequeira y Del Prato en que esta transformación operada por el teatro responde al cambio de paradigma de fin de siglo, pero que en Córdoba se hizo patente en su última década: «El paso de una noción homogénea y estable de identidad, propia del paradigma moderno, a una noción lábil y en permanente construcción de lo identitario introducida por la episteme posmoderna, produjo una modificación en la noción misma del sujeto quien pasa a ser la medida de las relaciones sociales» (Sequeira y Del Prato 2002: 269-270). El teatro del nuevo siglo se caracteriza por la exposición de sus propios procedimientos, moviéndose en una zona ambigua en la que, por un lado, se asume como ficción y, por el otro, esa misma conciencia expuesta lo sitúa en un lugar extraño a la realidad. Otra de las características que marca la impronta de la última década en el teatro local es la proliferación de nuevos dramaturgos que comenzaron a formarse en la década anterior y que constituyen un lugar central en el teatro actual.

La teatralidad de la última década en Córdoba es opaca, ambigua; es crítica y autocrítica, expone la insuficiencia de la palabra, busca nuevas formas de articulación del lenguaje y es particularmente significativa la recurrencia a los textos clásicos, reescritos bajo nuevas lecturas. Y es justamente porque la palabra ya no significa de la misma manera como lo hacía la antigua dramaturgia, porque los signos ya no están dirigidos a las causas, las causas y efectos aparecen mezclados, existen como posibilidades, se puede seguir relativamente un relato pero no explicar todo, la organización se percibe caótica. Rafael Spregelburd, actor, autor, director y teórico teatral (la multiplicidad de roles no es un caso aislado en el teatro independiente y es todo un signo), ve en la tragedia vacíos que dejan zonas abiertas, sin resolver, "puntos ciegos»; este es uno de los aspectos de la tragedia que recupera la nueva dramaturgia, en correspondencia con una realidad que muestra zonas indeterminadas y confusas. «Las teorías de la totalidad — dice Spregelburd - no han logrado crear una imagen concreta y por eso toman la forma de credo» (Seminario 2006).

La convivencia de distintas tendencias dentro de la escena dibujan un nuevo panorama teatral de riqueza y eclecticismo, en el que a la vez el 
pasado se actualiza, en términos deleuzianos, y tal vez, como sostenía Adorno, actualiza «aquello que quedó en otros tiempos sin resolver» (Adorno 2004: 34). Modificado el contexto, permanecen, tal vez no como tradición pero sí como herencia más o menos consciente. La crisis de la representación atraviesa el teatro, distintas nociones de lo post vienen a definir, en la teatralidad, el modo de nombrar un después de la supremacía de la palabra que surge en oposición a los conceptos de coherencia, continuidad, unidad, característicos del teatro de representación tradicional. El término propuesto hace décadas por Lehmann define un teatro que cuestiona significado y representación, coloca al cuerpo en su autorreferencialidad, pura presencia expuesta, en el centro de la construcción teatral y al texto como un componente más, al nivel de todos los otros elementos que intervienen. Nos parece interesante la definición de Óscar Cornago, para quien el teatro posdramático constituye «Un tipo de práctica escénica cuyo resultado y proceso de construcción ya no está previsto ni contenido en el texto dramático» (Cornago 2006). Como señalé, la exposición del artificio, el develamiento de los procedimientos tan frecuente en el teatro de los últimos años, denuncia la imposibilidad de representación de la realidad.

Muchos teóricos y hacedores teatrales argentinos vienen reflexionando sobre las transformaciones en la construcción escénica de los últimos años. Jorge Dubatti reconoce un nuevo canon teatral que define como un teatro de la diversidad, la atomización, en el que conviven, dice, «micropoéticas y microconcepciones estéticas, por lo que elegimos Ilamarlo el canon de la multiplicidad» (Dubatti 2006: 16). Similar es la percepción de Rafael Spregelburd, quien considera que no hay un centro respecto del que ubicarse como periferia, tal es la multiplicidad de voces que no hay un modelo fuerte que confrontar; en todo caso, lo hegemónico también ha pasado a ser para él esa multiplicidad que alberga sinnúmero de micropoéticas. Este director promueve la noción de teatro catástrofe, teatro de la complejidad, en contraposición al realismo heredado; un nuevo orden no sujeto a relaciones de causa y efecto; la apuesta a los pequeños cambios en determinados elementos, cuya suma opera un gran efecto transformador. La noción de catástrofe no niega categóricamente la causa, sino que se refiere a las causas como no identificables, por la velocidad a la que se mueve un sistema. Esta noción de la velocidad, y sus causas remotas como procedimiento, caracteriza desde hace mucho tiempo la escena contemporánea; la organización al interior de las estructuras se percibe caótica, los finales abiertos, imprecisos, porque, como plantea Spregelburd: "La resolución del conflicto deja al actor sin nada que hacer, hay que meterse en problemas. La misión del arte es dejar la vida en ridículo» (Seminario 2006). 
Finalmente, si queremos pensar la teatralidad cordobesa, no podemos dejar de mencionar las teorías de José Luis Valenzuela sobre el teatro de Paco Giménez, quien se refiere a los procedimientos que el emblemático director cordobés pone en juego, ya no como una estética, sino como una «ética» posmoderna. Este traslado del problema estético al terreno ético tiene que ver con la posición que el sujeto asume en el mundo, la respuesta que es capaz de dar y el modo en que resuelve su relación con la norma. En el teatro posmoderno, el actor se aparta justamente de los cánones de representación tradicionales y lo que lo mueve es una "voluntad originaria de acción». «Y es posible - dice-que ese impulso dependa de un pudoroso retiro a segundo plano de las técnicas eficaces y las estéticas, afirmándose en su lugar una ética» (Valenzuela 2004: 23-24). Valenzuela sustenta sus teorías en las Tecnologías del yo, de Foucault, en el modo en que el individuo tramita su sujeción a la regla, a través de tecnologías que pone en marcha sobre sí mismo, y en las de Lacan, atendiendo a las estructuras clínicas. De este cruce resulta que el actor contemporáneo estaría afirmado en una ética "sacrílega», asociada a la estructura perversa, en tanto desafía la ley; la transgresión está lanzada justamente a la idea de representación. La labor actoral es para Valenzuela «la activación de un complejo dispositivo de autoproducción y se cuenta entre las disciplinas encaminadas al "gobierno de sí", sabiendo que ningún "yo" la gobernará, y que lo gobernado no será un objeto de contornos precisos» (Valenzuela 2004: 31-32).

Creo que la dramaturgia contemporánea está claramente atravesada por esta última ética y, consecuentemente, los procedimientos actorales que de ella devienen tienen correspondencia con sus características: la provocación, la profanación de los métodos consagrados, la exposición de los mecanismos teatrales. Dice Valenzuela que «el perverso hace o pone en acto lo que el histérico solo es capaz de imaginar» (Valenzuela 2004: 44); lo que se pervierte en esta ética es la norma actoral. Las distintas éticas a las que recurre el actor en el teatro posmoderno operan como figura y fondo una respecto de las otras, fluctúan en forma permanente constituyendo, en sus palabras, «una zona de permanencia entre deslizamientos [...] una herramienta dramatúrgica [...] una unidad de producción deseante en torno del actor, como una máquina deseante» (Valenzuela 2004: 52). Son modos de composición no impuestos, no diseñados de antemano, que surgen de un trabajo simple, de una economía extrema y que puede complejizarse al infinito.

Valenzuela también pone en juego los conceptos de Deleuze y Guattari sobre la esquizofrenia. A fin de ejemplificar ciertas formas de construcción, cita: «Pasa de un código a otro, mezclando todos los códigos, en 
un deslizamiento rápido [...] no invocando la misma genealogía, no registrando de la misma manera el mismo acontecimiento, [...] con el riesgo de atiborrarlo con todas las disyunciones que ese código estaba dispuesto a excluir» (Valenzuela 2004: 15). En las obras que se ponen en escena en Córdoba en los últimos años asistimos a la detención del discurso que luego fuga en el vacío; a abruptas variaciones de códigos; información que se ofrece fragmentada, que se interrumpe para luego ser retomada; los planos discursivos y semánticos se abren y quedan inacabados o ambiguos. Estas operaciones hacen que se produzca esa «indiferenciación de la producción y del producto» de la que habla Valenzuela, de la que hablan Deleuze y Guattari. Se asiste a la producción del producto y no se recibe un producto acabado. Lo que hay es la creación, cada vez, de un lenguaje que toma forma colectivamente, inédito, que supone la aceptación de un riesgo, que confía en un «acuerdo inteligente», que va de «acto en acto [...] y vuelve a jugarse entero cada vez» (Zourabichvili 2004: 83).

Si el teatro da cuenta de nuevas definiciones de la realidad, da lugar a la gran crisis posmoderna, que es la del sentido. En una relación de figurafondo, como señala Spregelburd, el significado sería la figura y el sentido sería el fondo, fondo inasible por completo por la imposibilidad de ser percibido en términos de significado. Cada vez que se logra visualizar, se convierte en figura y deja un nuevo fondo detrás (un sentido) que nuevamente se vuelve inalcanzable. Arlindo Machado por su parte, nos advierte de la necesidad de superar la dualidad sentido-no sentido en el arte contemporáneo, superar también la función pragmática y de comunicación del lenguaje (yo digo de los lenguajes), «para verlo como un fenómeno turbulento, responsable principal de las crisis humanas de desorden, inestabilidad y descubrimiento» (Machado 2000: 134). De este modo, ya no se trata de una contradicción o de una dualidad del sentido que hay que descubrir, sino que este es presentado y aceptado en toda su ambigüedad. Este fin de la dicotomía sentido-no sentido, esta ambigüedad, se advierte claramente en el teatro de Córdoba de los últimos años. Sus procedimientos oscilan entre dos extremos: desde un concepto de máxima austeridad hasta la exhibición de manera exacerbada de la incorporación de otros medios, operando por superposición, saturando la escena. La preocupación no está puesta en el sentido, es puro procedimiento y es a través de él que deviene el sentido.

Asimismo, Machado señala que estos modos de construcción «apuntan a una nueva gramática [...] y también hacia la necesidad de unos nuevos parámetros de lectura por parte del sujeto» (Machado 2000: 203). El nuevo parámetro, creo, es la ausencia de parámetros, cualquier intención de una lectura lineal se vería frustrada frente a estas «imágenes migratorias», 
estas «figuras en permanente tránsito», como él las nombra, sería intentar inútilmente la aprehensión de ese fondo que constituye el sentido, del que habla Spregelburd, que más se desvanece mientras más intentamos fijarlo. Lo que podemos captar de estas estructuras son solo fragmentos, insinuaciones, imágenes fugaces, distorsiones, reconocer sin demasiada certeza algunos desechos que se recuperan y transforman. Por ser fragmentarios estos modos de construcción, por ser apenas insinuaciones, por la distorsión con que se presentan, nos hacen saber que son solo «posibilidades», alguna de las innumerables que admite. Y cada posibilidad en un punto deja afuera a las otras, forzando una toma de posición, al tiempo que inevitablemente todas se alojan en forma simultánea. De este modo, puede entenderse el teatro contemporáneo como un simulacro, que no es copia ni original, que existe en sí mismo y por sí mismo, que solo aspira a aproximaciones difusas, que no se propone definiciones en términos de realidad o ficción.

\section{Conclusión}

El mayor cambio operado en el campo teatral en Córdoba a partir del fin de la dictadura, y que empieza a profundizarse aún más en la década de 1990, se dio en relación con una nueva percepción de la realidad y de otra experiencia del sujeto en el mundo. Esta nueva percepción puso en crisis el sentido, las nociones de tiempo y espacio, modificando los conceptos de representación. La escena es atravesada por la idea de simultaneidad, se concibe heterogénea, en devenir, se conforma como un espacio de circulación de múltiples medios sin privilegiar uno sobre los otros. El nuevo canon, como plantea Jorge Dubatti, es el de la multiplicidad, que fuera de su misma abstracción no admite definiciones, impide la clausura, se presenta en permanente construcción.

Dentro de este cambio en la configuración del campo teatral devienen nuevos regímenes discursivos que conforman espacios inéditos, en los que se profundiza la reflexión sobre la práctica, pero ya no solo por parte de los sujetos vinculados al campo literario o al de la crítica, sino por parte de los propios artistas, quienes toman la palabra y esta extensión opera el desplazamiento de un pensamiento sobre la práctica a un pensamiento en la práctica. Esto y una nueva generación de dramaturgos que piensa y escribe desde nuevos presupuestos son sin duda las novedades que ingresaron en las últimas dos décadas.

El nuevo estado tiene su soporte fundamentalmente en un cambio en la noción de tiempo que inaugura un nuevo paradigma; el tiempo se concibe como duración, como pura diferencia; se deja atrás definitivamente la idea de una división entre pasado, presente, futuro, sobre todo en 
Latinoamérica, donde conviven tiempos heterogéneos: premodernidad, modernidad, posmodernidad; distintas dimensiones temporales que se actualizan unas en las otras.

Me pregunto con Claudia Kozak: «¿Cuál será el resto de acabamiento que las obras exhiban para no obturarse en su punto presente de utopía alcanzada?» (Kozak 2004: 7); y acordamos en que tal vez «Solo bastaría, quizá, con no regodearse en una "conquista" del presente ya consumado que nos impida pensar el arte como transformación» (Kozak 2004: 8). El teatro, que es menos reproducción que producción en acto, seguirá pensándose como transformación, volverá a jugarse entero cada vez. 


\section{REFERENCIAS BIBLIOGRÁFICAS}

ADORNO, Theodor (2004). Teoría estética. Madrid: Grupo Editorial Akal.

BALANDIER, Georges (1998). El desorden. La teoría del caos y las ciencias sociales. Elogio de la fecundidad del movimiento. Barcelona: Editorial Gedisa.

BEMJAMIN, Walter (2009). Estética y política. Buenos Aires: Las Cuarenta Editorial.

CORNAGO, Óscar (2006). «Teatro postdramático: las resistencias de la representación». Consultado el 10 de abril de 2013 de http://artesescenicas. uclm.es/archivos_subidos/textos/290/teatropostdramatico_ocornago. pdf

DELEUZE, Gilles (2002). Diferencia y repetición. Buenos Aires: Amorrortu Editores.

DUBATTI, Jorge (2006). Seminario «El teatro por sus protagonistas». Universidad Nacional de Córdoba, comunicación personal.

FOUCAULT, Michel (1979). La arqueología del saber. México D. F.: Siglo XXI Editores.

KOZAK, Claudia (2004). «La conquista del presente. Algunas reflexiones en torno del concepto de simultaneidad en el eje arte/técnica». Consultado el 10 de abril de 2013 de http://ludion.com.ar/articulos.php?articulo_id=19

MACHADO, Arlindo (2000). El paisaje mediático. Sobre el desafío de las poéticas tecnológicas. Buenos Aires: Libros del Rojas.

PRIETO STAMBAUGH, Antonio (2007). «Performance y teatralidad liminal: hacia la represent-acción». Consultado el 10 de abril de 2013 de http:// artesescenicas.uclm.es/archivos_subidos/textos/129/Performance\%20 y\%20teatralidad\%20liminal.pdf

SEQUEIRA, Jazmín y DEL PRATO, María (2002). «La representación (imposible) de los desaparecidos. Procedimientos y discursos poético/políticos del teatro contemporáneo sobre la última dictadura militar». En Interpelaciones. Hacia una teoría critica de las escrituras sobre la dictadura y la memoria. Córdoba: Centro de Estudios Avanzados, Universidad Nacional de Córdoba.

SPREGELBURD, Rafael (2006). Seminario «El teatro por sus protagonistas». Universidad Nacional de Córdoba, comunicación personal.

VALENZUELA, José Luis (2004). Las piedras jugosas. Aproximación al teatro de Paco Giménez. Buenos Aires: Instituto Nacional de Teatro.

ZOURABICHVILI, François (2004). Deleuze. Una filosofía del acontecimiento. Buenos Aires: Amorrortu Editores. 